\section{Orbital metastasis from cutaneous melanoma}

\author{
Loukia Tsierkezou, Peter Cikatricis, \\ Parveen Abdullah, Samer Elsherbiny \\ Birmingham Midland Eye Centre, City \\ Hospital, Birmingham, UK
}

\begin{abstract}
We report a case of a metastatic cutaneous melanoma to the orbit. A 60-year-old Caucasian male presented with a 2-day history of left-sided ocular pain, lid swelling and chemosis. Initially, this was treated as conjunctivitis with no signs of improvement. Four days later, the patient developed left proptosis, mechanical ptosis, left esotropia and diplopia. Computed tomography scan of the orbit demonstrated marked thickening of the lateral rectus muscle. The patient was treated as pseudotumor. Subsequent biopsy revealed malignant cutaneous melanoma. The patient had a history of cutaneous melanoma excised 15 years previously. Further imaging showed advanced metastatic disease in the brain, the lung and the liver. The patient passed away five months after initial presentation. Cutaneous melanoma metastasizing to the orbit has poor prognosis. Patients often have advanced disease at the time of presentation and orbital metastases may be the initial sign. A detailed history is paramount in making timely diagnosis.
\end{abstract}

\section{Introduction}

Metastatic cutaneous melanoma to the eye and the orbit is very rare. ${ }^{1-4}$ In autopsy series of metastatic cutaneous melanoma patients, the numbers of orbital metastases are reported ranging from 1-33\%. ${ }^{5}$ Orbital metastases from cutaneous melanoma account for $5.3-15 \%$ from all metastatic tumors to the orbit. ${ }^{6}$ The most common primary source of metastatic tumors to the orbit is breast cancer (42\%), followed by lung cancer (11\%).,3,5,8 Cutaneous malignant melanoma is reported to be the fourth most common. ${ }^{4}$ The predominant site of orbital metastases in breast cancer and melanoma tends to be the orbital fat and extra-ocular muscles, whereas in the case of lung cancer it is the bony orbit. ${ }^{9}$ Frequently, the orbital involvement presents long after the primary disease and sometimes it represents the first sign of a metastatic disease before the primary tumor is found. Therefore, a thorough history and physical examination (by the appropriate specialist) is very important. ${ }^{10}$

Orbital melanomas derive from melanocytes of the uveal tissues or characterize distant metastasis of cutaneous melanomas to the orbit. They can be classified into primary and secondary orbital melanomas. Primary orbital melanomas are extremely rare whereas secondary orbital melanomas are more common. Orbital melanomas usually represent massive extra-scleral extensions of uveal melanomas. ${ }^{11}$

\section{Case Report}

A 60-year-old Caucasian male presented with a 2-day history of unilateral, left-sided ocular pain, lid swelling and chemosis. At first, this was treated as conjunctivitis with topical antibiotics by his general practitioner with no signs of improvement. Left eyelid swelling, chemosis and limited ocular movements on abduction and adduction were noted. The visual acuity in the right eye was $6 / 6$ and in the left was $6 / 9$. Intraocular pressures were 13 $\mathrm{mmHg}$ in the right eye and $19 \mathrm{mmHg}$ in the left eye. Fundal examination was normal. Optic nerve function was preserved with normal color vision and pupils equal and reactive to light without afferent pupillary defect. The first impression of the casualty officer was allergic reaction and the patient was discharged home with oral antihistamines and steroid eye drops. Four days later the patient was reviewed. On examination, there was marked left proptosis, mechanical ptosis, left esotropia and diplopia.

The patient was otherwise systemically well with a history of atopy. A computed tomography (CT) scan of the orbit demonstrated markedly thickened belly of the left lateral rectus muscle with musculo-tendon junction involvement in keeping with pseudotumor (Figure 1A). A CT scan of the head revealed $2 \times 2 \mathrm{~cm}$ low attenuation area in the left parietal area, which required further imaging. Blood tests showed raised C-reactive protein (CRP) $(160 \mathrm{mg} / \mathrm{L})$, erythrocyte sedimentation rate (ESR) (83 $\mathrm{mm} / \mathrm{hr}$ ) and slightly deranged liver function tests. Thyroid function was normal. The patient was initially treated as a pseudotumor with suspected myositis. Oral prednisolone, oral ibuprofen and topical treatment with prednisolone eye drops were prescribed, again, with no signs of improvement. The patient subsequently gave a history of previously excised skin melanoma 15 years ago.

A biopsy of the left orbital and lateral rectus muscle mass subsequently revealed malignant melanoma. Sections of the biopsy from the left orbital mass showed fibrovascular tissue, which was infiltrated by lymphocytes, plasma cells and macrophages. There were scattered groups and clusters of atypical cells with hyper-
Correspondence: Loukia Tsierkezou,

Birmingham Midland Eye Centre, City Hospital, Dudley road, B18 7QH, Birmingham, UK.

Tel. +44 1215076799 .

E-mail: Itsier@hotmail.com

Key words: cutaneous melanoma, metastases, orbit.

Contributions: LT, data collection, analysis and interpretation, manuscript preparing, revising and editing of the final version submitted for publication; PC, images, histopathology report and slides selection and editing, manuscript critical review and final approval; PA, histopathology report and slides providing; SE-S, clinical data providing, manuscript critical review and approval of the final version submitted for publication.

Conflict of interests: the authors declare no potential conflict of interests.

Received for publication: 9 March 2012.

Revision received: 11 June 2012.

Accepted for publication: 15 June 2012.

This work is licensed under a Creative Commons Attribution NonCommercial 3.0 License (CC BYNC 3.0).

CC Copyright L. Tsierkezou et al., 2012

Licensee PAGEPress, Italy

Eye Reports 2012; 2:e4

doi:10.4081/eye.2012.e4

chromatic and pleomorphic nuclei. The nuclei were oval, round to elongated and there was melanin pigment in the background. Immunohistochemistry was performed and the cells were positive for S100, Melan-A and HMB45. CD68 was positive in the background macrophages but the tumor cells were negative for it (Figure 2). A diagnosis of metastatic orbital melanoma was made based on patient's history of cutaneous melanoma. Further investigations including a whole body CT-scan revealed metastases in the lungs, the liver with possible peritoneal and serosal deposits (Figure 1B and C). Magnetic resonance imaging of the brain and orbit showed metastases in the brain and left lateral rectus (Figure 3). The patient was referred to the oncologists for further management. Exenteration of the orbit was not recommended in the first instance due to poor life expectancy. Two months later Bscan ultrasonographic examination revealed an intraconal mass of $14 \mathrm{~mm}$ in diameter. Repeat CT demonstrated increased number of metastases in the lungs and the liver with new pelvic and peritoneal lesions. The oncologists recommended evisceration and a month later debulking of the orbit. Removal of the orbital and brain masses was carried out by the neurosurgeons. The patient passed away shortly afterwards, five months after orbital presentation. 


\section{Discussion}

Differentiation between primary and secondary orbital melanomas is difficult. Fine needle aspiration biopsy can help provide information about the origin of any orbital tumor. ${ }^{12}$ De Bustros et al. ${ }^{1}$ based their diagnosis of metastatic disease in accordance with the history or presentation of other metastatic lesions at the time of diagnosis. In their series they emphasize that the eye can be the initial site of recurrence of cutaneous melanoma. Even in cases where there is no known history of skin lesion excisions and a metastatic orbital melanoma is suspected, the dermatologists should search for a cutaneous or mucosal melanoma. ${ }^{2}$ Many patients (like our patient) may not remember to mention a history of previously excised skin lesion. Therefore, it is very important to actively seek information in every case with intraocular or orbital tumor.

Ramesh et al..$^{12}$ reviewed literature regarding intraocular sites of cutaneous melanoma metastases. In total, 75\% involved the uvea. De Bustros et al. ${ }^{1}$ in their series of 12 eyes report the eye as a potential initial site of a clinically identifiable recurrence of cutaneous malignant melanoma. Valenzuela et al. ${ }^{9}$ in a chart review of 80 patients established that the orbit was the first site of presentation of a metastatic tumor in $15 \%$ of the cases. Generally, a metastatic tumor may present with ophthalmic symptoms before the diagnosis of the primary source of tumor has been established, ${ }^{4,5,13}$ Orbital metastases in some cases occur after long, disease-free intervals. ${ }^{6,10}$ In our case ocular metastases presented 15 years following the excision of skin melanoma with widespread metastases. The mean survival of patients with intraocular metastasis of melanoma is generally poor. Zografos et $a l^{3}$ in
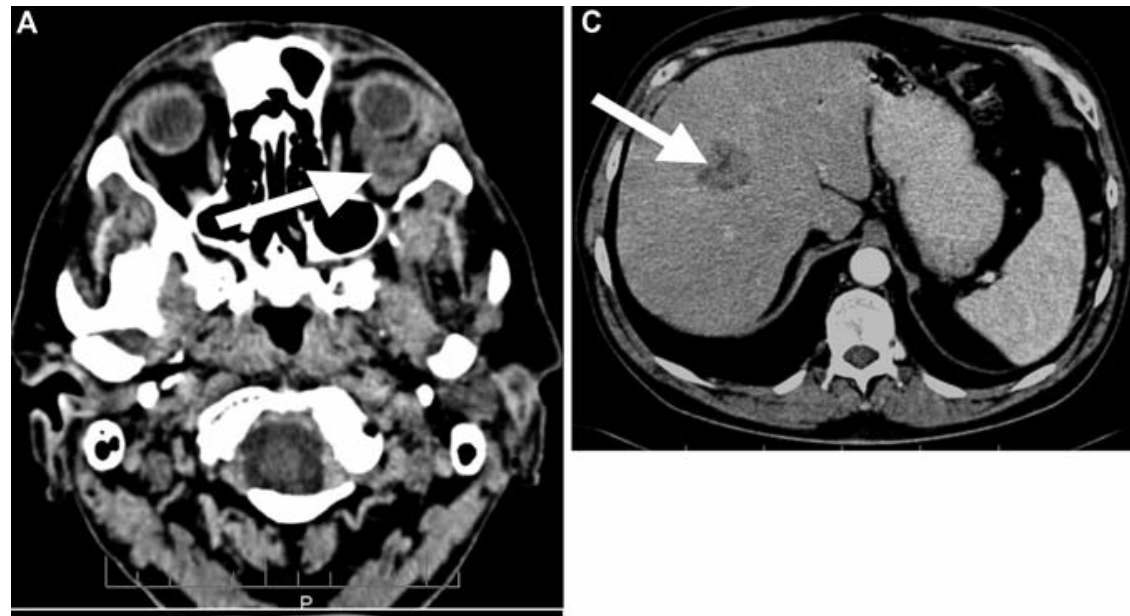

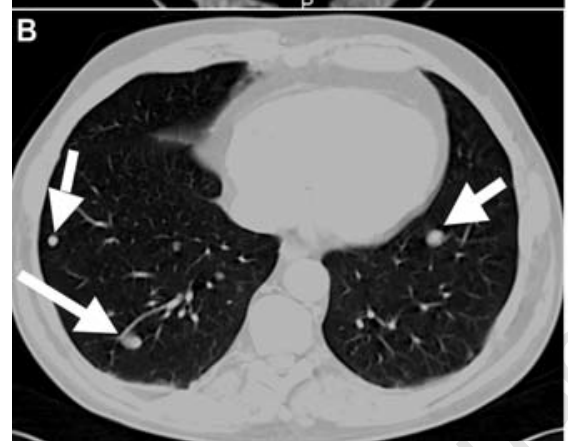

Figure 1. A) An axial computed tomography (CT) scan of brain and orbit showing markedly thickened lateral rectus at the muscle belly, which is involving the musculo-tendon junction (white arrow). B) Axial CT scan of the lungs showing multiple deposits (white arrows). C) Axial CT scan showing metastasis in the liver (white arrow).

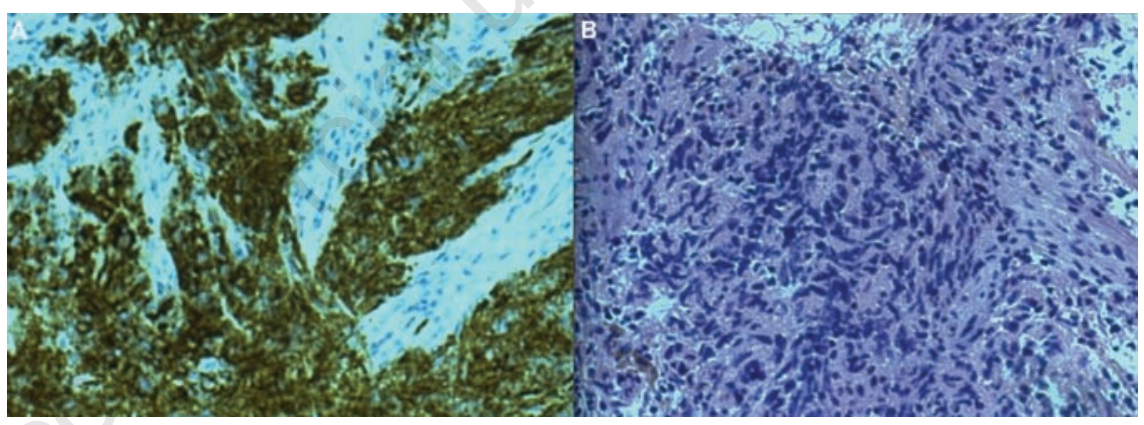

Figure 2. (A) Histopathology slides showing Melan-A immuno stain for melanoma. (B) Hematoxylin and eosin stain (see text).
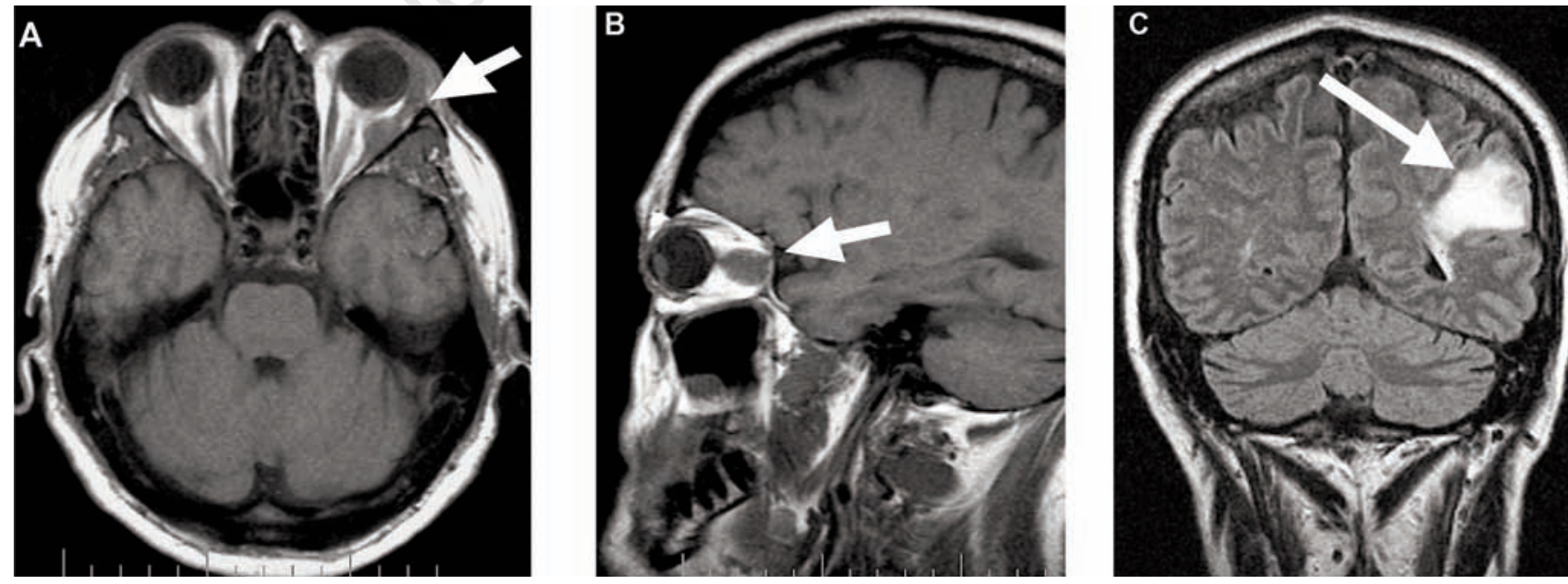

Figure 3. A and B) Magnetic resonance imaging scan of the orbit shows focal and globular swelling of the lateral rectus muscle representing metastasis. C) A T1 weighted coronal magnetic resonance imaging scan of the brain with contrast enhancement demonstrates lesion in the parietal region and surrounding oedema (white arrow). 
Table 1. Relative incidence of cutaneous melanoma metastatic to the orbit and mean survival.

\begin{tabular}{|c|c|c|c|c|c|c|}
\hline $\begin{array}{l}\text { Authors and } \\
\text { references }\end{array}$ & $\begin{array}{l}\text { Type of } \\
\text { study }\end{array}$ & $\begin{array}{l}\text { No. of } \\
\text { patients }\end{array}$ & $\begin{array}{l}\text { Orbital } \\
\text { metastasisfrom } \\
\text { all causes }\end{array}$ & $\begin{array}{l}\text { Metastatic orbital } \\
\text { cutaneous } \\
\text { melanoma }\end{array}$ & $\begin{array}{l}\text { Mean timing of } \\
\text { ocular } \\
\text { presentation }\end{array}$ & Mean survival \\
\hline Ferry \& Fond ${ }^{7}$ & Clinical & 227 & 28 & 1 & & 7.4 months \\
\hline Bond et al. ${ }^{10}$ & Case reports & 2 & 2 & 2 & 7.5 years & 8 months \\
\hline De Bustros et al. ${ }^{1}$ & Clinical & 12 & 0 & 0 & 3.25 years & 2.4 months \\
\hline Char et al. ${ }^{13}$ & Clinical & 31 & 31 & 5 & & 16 months \\
\hline 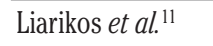 & Clinical & 15 & 15 & 1 & & 16.6 months \\
\hline Zografos et al. ${ }^{3}$ & Clinical & 20 & 7 & 5 & 5.5 years & 19.7 months \\
\hline Holland et al..$^{14}$ & Clinical & 20 & 20 & 0 & 5.3 years & 14.7 months \\
\hline $\begin{array}{l}\text { Rosenberg and } \\
\text { Finger }^{5}\end{array}$ & Review & $\begin{array}{c}93 \\
\text { patients in } \\
\text { case reports }\end{array}$ & 29 & 29 & 5.5 years & 7.5 months \\
\hline Ullah et al. ${ }^{4}$ & Case report & 1 & 1 & 1 & & 6 months \\
\hline Valenzuela et al. ${ }^{9}$ & Clinical & 80 & 80 & 16 & 3.6 years & 18 months \\
\hline
\end{tabular}

a retrospective clinical study of 15 eyes have reached similar figures of mean survival to those reported in other literature. This corresponds to a mean survival time of patients with intraocular metastasis between 2.5 and 9.0 months. The mean survival for orbital metastatic melanoma was 19.7 months. Ferry and Fond ${ }^{7}$ carried out a clinical-pathological study of 227 patients with carcinoma metastatic to the eye or the orbit and the mean survival was 7.4 months from the time of ocular/orbital involvement. Holland et al. ${ }^{14}$ reported the mean survival to be at 14.7 months (Table 1). Patients who present with ocular metastases from cutaneous melanoma have usually widespread systemic disease at the time of ocular manifestation., ${ }^{3,415}$ At presentation, our patient had widespread systemic metastases and 5 months survival.

Melanoma in the orbit preferentially involves extra-ocular muscles. ${ }^{3,5}$ CT scanning demonstrates smooth enlargement of the muscle. ${ }^{6}$ As described previously, the CT of the orbit in this case revealed a markedly thickened lateral rectus at the muscle belly. Therefore, diplopia and extraocular muscles limitations are common presenting signs. ${ }^{6,8,15}$ Proptosis and pain usually present in the early clinical course of the disease as well. ${ }^{9}$ In certain cases, debulking of the mass may be a palliative measure..$^{3,6,16}$ Orbital exenteration and surgical treatment of brain metastasis represent in some options too aggressive of a management of patient with poor prognosis and short life expectancy. Among the various possible treatment options gamma knife radiosurgery maybe an effective treatment option for orbital tumors as well as intracranial tumors. Kim et $a l^{17}$ in a study of 15 patients with orbital tumors (2 of which were metastatic tumors) showed that in the 13 patients whose vision was preserved preoperatively, 6 patients showed improvement in visual acuity, 4 patients showed no change in vision, and 3 patients showed deterioration. However, three patients with malignant lesions had to under- go another operation due to tumor progression. Circumscribed proton beam radiotherapy or global photon beam radiotherapy at relatively high irradiation doses, seem to achieve some favorable results. ${ }^{3}$

\section{Conclusions}

In patients with a known history of cutaneous melanoma presenting with ocular inflammation, a high index of suspicion for metastatic disease should be maintained. Orbital metastases of malignant cutaneous melanoma are very rare but they may be the first sign of manifestation of advanced metastatic disease. The diagnosis is based on a previous history of cancer. Most frequently it involves the extra-ocular muscles. Imaging is an important tool in detecting and localising the tumour, defining its characteristics and extent within the orbit, as well as in establishing the systemic spread of the disease. The life expectancy is short. Thus, in the majority of cases any treatment may only be palliative. The diagnosis of orbital metastases is very important as it can lead to early diagnosis and it can establish the extent of the primary disease, in order to improve the patient's quality of life with palliative management.

\section{References}

1. De Bustros S, Augsburger JJ, Shields JA, et al. Intraocular metastases from cutaneous malignant melanoma. Arch Ophthalmol 1985;103:937-40.

2. Fujii K, Komurasaki Y, Kanno Y, Ohgou N. Unilateral exophthalmos due to orbital metastasis from a contralateral intraocular melanoma. Eur J Dermatol 1998;8:343-6.

3. Zografos L, Ducrey N, Beati D, et al. Metastatic melanoma in the eye and orbit.
Ophthalmology 2003;110:2245-56.

4. Ullah T, Gurwood AS, Myers MD. Ocular metastasis of cutaneous malignant melanoma. Optometry 2009;80:572-8.

5. Rosenberg C, Finger PT. Cutaneous malignant melanoma metastatic to the eye, lids and orbit. Surv Ophthalmol 2008;53:187202.

6. Ahmad SM, Esmaeli B. Metastatic tumors of the orbit and ocular adnexa. Curr Opin Ophthalmol 2007;18:405-13.

7. Ferry AP, Fond RL. Metastatic carcinoma to eye and orbit. Arch Ophthalmol 1974;92: 276-86.

8. Pedroli GL, Hamedani M, Barraco P, et al. Orbital metastasis in malignant melanoma. J Fr Ophthalmol 2001;24 286-90.

9. Valenzuela AA, Archibald CW, Fleming B, et al. Orbital metastasis: clinical feaures, management and outcome. Orbit 2009;28: 153-9.

10. Bond JB, Wesley RE, Reynolds VH, et al. Orbital metastasis from cutaneous melanoma. South Med J 1985;79:1439-42.

11. Liarikos S, Rapidis AD, Roumeliotis A, Angelopoulos AP. Secondary orbital melanomas: analysis of 15 cases. J Craniomaxillofac Surg 2000;28:148-52.

12. Ramesh K, Marshall JWV, Wharton SB, Dhillon B. Intraocular metastases of cutaneous melanoma: a case report and review of the literature. Eye 1999;13:247-50.

13. Char DH, Miller T, Kroll S. Orbital metastases: diagnosis and course. $\mathrm{Br} \mathrm{J}$ Ophthalmol 1997;81:386-90.

14. Holland D, Maune S, Kovács G, Behrendt S. Metastatic tumors of the orbit: A retrospective study. Orbit 2003;22:15-24.

15. Drummond SR, Fenton S, Pantilidis EP, et al. A case of cutaneous melanoma metastatic to the right eye and left orbit. Eye 2003;17:420-2.

16. Orcutt JC, Char DH. Melanoma metastatic to the orbit. Ophthalmology 1988;95:1033-7.

17. Kim MS, Park K, Kim JH, et al. Gamma knife radiosurgery for orbital tumors. Clin Neurol Neurosurg 2008;110:1003-7. 